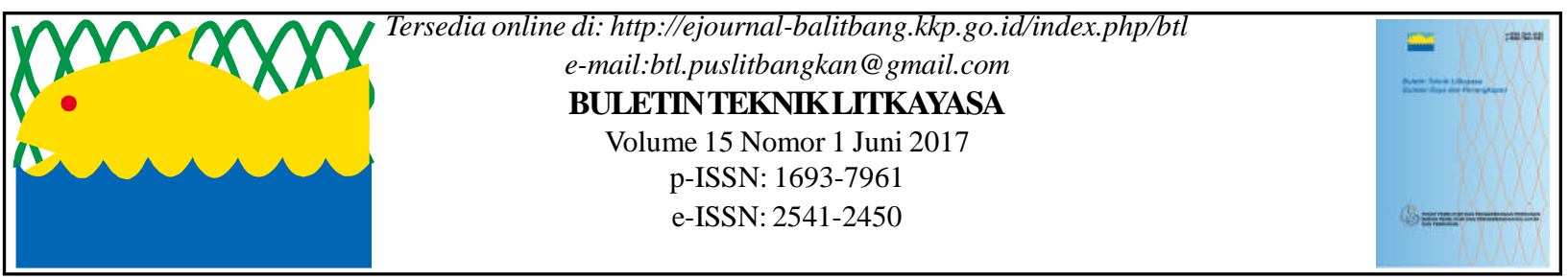

\title{
OPERASIONAL ALAT TANGKAP PUKAT CINCIN MINI (MINI PURSE SEINE) DI TELUK TOMINI OLEH NELAYAN DI GORONTALO
}

\author{
Enjah Rahmat dan Bambang Witdiarso \\ Teknisi Balai Penelitian Perikanan Laut, Jakarta \\ Teregistrasi I tanggal: 06 Maret 2017; Diterima setelah perbaikan tanggal: 08 Juni 2017; \\ Disetujui terbit tanggal: 13 Juni 2017
}

\section{PENDAHULUAN}

Teluk Tomini termasuk dalam Wilayah Pengelolaan Perikanan (WPP) 715 mempunyai potensi perikanan yang cukup melimpah terutama untuk sumber daya ikan pelagis. Usaha penangkapan ikan pelagis kecil oleh nelayan Teluk Tomini pada umumnya menggunakan alat tangkap pukat cincin mini (mini purse seine), sedangkan untuk ikan pelagis besar menggunakan pancing ulur (hand line).

Gorontalo merupakan kota pelabuhan di pesisir Teluk Tomini. Lokasinya cukup strategis, sehingga memudahkan nelayan untuk mendaratkan ikan hasil tangkapannya. Di Gorontalo terdapat tempat pendaratan ikan yang cukup penting yaitu Pusat Pendaratan Ikan (PPI) Tenda. Di PPI Tenda banyak didaratkan ikan hasil tangkapan pukat cincin mini. Ikan hasil tangkapan nelayan dipasarkan lokal tetapi pada saat hasil tangkapan melimpah ikan dipasarkan ke beberapa daerah lain di Sulawesi, bahkan sampai ke Surabaya, Jawa Timur.

Pada tahun 2015 kapal pukat cincin mini yang mendaratkan hasil tangkapannya di PPI Tenda ratarata 105 unit kapal/bulan dengan produksi rata-rata 168 ton/bulan. Dengan demikian peranan nelayan dan armada pukat cincin mini sangat penting dalam peningkatan produksi ikan di Gorontalo. Makalah ini membahas tentang teknik pengoperasian pukat cincin mini oleh nelayan di Gorontalo.

\section{POKOK BAHASAN \\ Bahan dan Metode}

Materi bersumber dari hasil wawancara dengan nakhoda kapal dan nelayan pukat cincin mini di PPI Tenda Kota Gorontalo pada bulan Juni 2016. Alatalat dan bahan yang digunakan terdiri dari alat ukur panjang (meteran), alat ukur berat (timbangan) dan buku identifikasi ikan pelagis (FAO, 2000).

\section{HASIL DAN BAHASAN \\ Spesifikasi Kapal}

Armada pukat cincin mini yang melakukan aktivitas bongkar muat di PPI Tenda Gorontalo pada periode tahun 2015 sampai bulan Juni 2016 tercatat sebanyak 50 unit kapal dengan bobot kapal 4-32 GT; meliputi ukuran d 10 GT (26\%), 11-20 GT (14\%), 2130 GT (37\%) dan e $\geq 30$ GT (23\%). Kisaran rata-rata jumlah trip penangkapan per bulan adalah 2 kali sampai 9 kali dan jumlah kapal yang mendarat ratarata 105 unit kapal/bulan dengan jumlah produksi ratarata 168 ton/bulan. Contoh spesifikasi kapal motor yang mengoperasikan alat tangkap pukat cincin mini diperlihatkan pada Tabel 1.

Tabel 1. Spesifikasi kapal pukat cincin mini contoh di Gorontalo

\begin{tabular}{lll}
\hline \multicolumn{1}{c}{ Spesifikasi } & \multicolumn{1}{c}{$\begin{array}{c}\text { KM Bulls } \\
\text { Indo Raya 05 }\end{array}$} & \multicolumn{1}{c}{ KM Fajar 05 } \\
\hline Ukuran kapal (PxLxD) & $23,00 \times 4,90 \times 1,50 \mathrm{~m}$ & $20,90 \times 5,03 \times 1,45 \mathrm{~m}$ \\
Bobot kapal (GT) & $30 \mathrm{GT}$ & $30 \mathrm{GT}$ \\
Jumlah ABK & 30 orang & 29 orang \\
Mesin penggerak & 1 unit, 350 PK & 1 unit, 360 PK \\
Alat navigasi & GPS, kompas, & GPS, kompas, \\
& radio komunikasi & radio komunikasi \\
\hline
\end{tabular}

Korespondensi penulis:

JIn. Muara Baru Ujung, Komp. Pelabuhan Perikanan

Nizam Zachman, Jakarta Utara 
Kapal pukat cincin mini dilengkapi juga dengan mesin lampu untuk penerangan, mesin gardan untuk menarik jaring pada saat dioperasikan. Sedangkan untuk menampung ikan hasil tangkapan, tersedia 9 palka ikan dengan kapasitas 2 ton ikan per palka. Untuk mempertahankan mutu ikan, ikan hasil tangkapan disimpan dalam palka dan diberi es curah yang dicampur dengan air laut. Contoh kapal pukat cincin mini Gorontalo disajikan pada Gambar 1. Anak buah kapal, terdiri dari juru mesin, juru minyak, juru selam, juru masak dan ABK biasa.

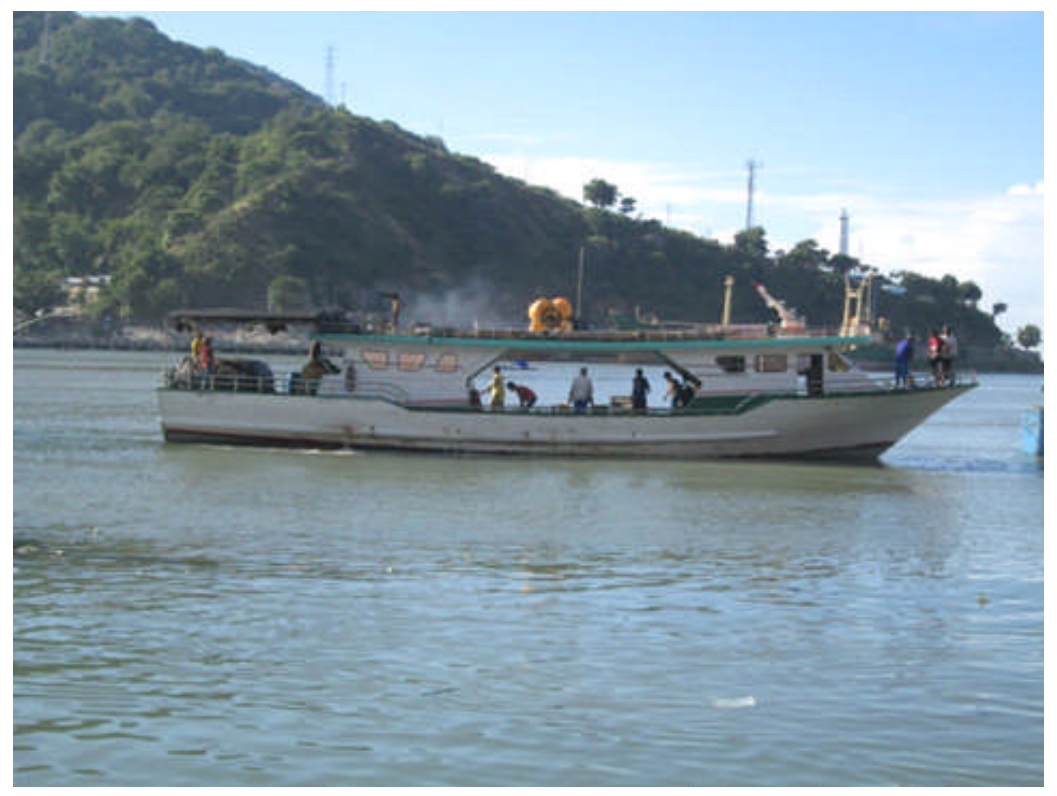

Gambar 1. Kapal motor pukat cincin mini di Gorontalo, Juni 2016

\section{Spesifikasi Jaring (Pukat Cincin)}

Pukat cincin terdiri dari kantong (bunt), badan jaring, sayap, jaring pada pinggir badan jaring (selvedge), tali ris atas (floatline), tali ris bawah (leadline), pemberat (sinkers), pelampung (floats), dan cincin (purse rings).
Panjang jaring yang digunakan nelayan Gorontalo (nelayan contoh) adalah 300 meter dan dalam kantong 60 meter. Kantong tempat berkumpulnya ikan memiliki ukuran mesh size 1,00 inchi; sedangkan mesh size badan jaring, bagian sayap dan selvedge berukuran masing-masing 1,25 inchi, 1,50 inchi dan 2,00 inchi (Gambar 2).

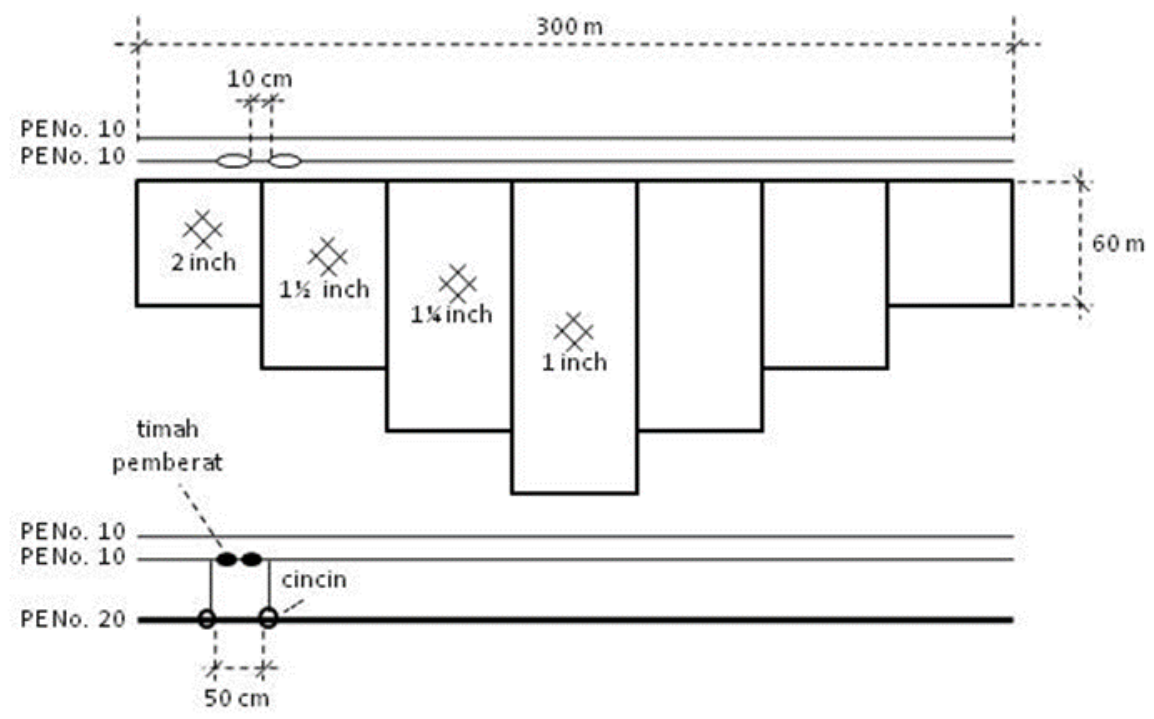

Gambar 2. Desain pukat cincin mini di Gorontalo 


\section{Pengoperasian Pukat Cincin Mini}

Pengoperasian alat tangkap, ditentukan berdasarkan hasil pengamatan para penyelam (sekitar 5 orang). Para penyelam menaksir kelimpahan ikan di perairam sekitar rumpon dan memantau arah arus untuk memperkirakan pemasangan jaring.

Jaring dioperasikan pada pagi hari mulai pukul 5 pagi, waktu setting berlangsung selama setengah jam. Dalam 1 trip pukat cincin mini dioperasikan 1 sampai 2 kali setting, tergantung hasil tangkapan.

Operasi penangkapan di sekitar rumpon dengan target penangkapan ikan pelagis kecil antara lain layang (Decapterus spp), selar (Selar, Selaroides), ikan pelagis besar seperti cakalang (Katsuwonus pelamis), tongkol (terutama tongkol lisong (Auxis rhocel) dan ikan tuna (Thunnus spp.) yang masih muda. Tahapan operasional jaring adalah sebagai berikut:

1. Ujung jaring diturunkan, kapal bergerak melingkar mengelilingi rumpon sambil mengulur tali dan jaring sampai bertemu dengan ujung jaring.

2. Tali cincin ditarik sampai cincin naik keatas kapal

3. Pengopeasian jaring berlangsung selama 1 jam
4. Jaring ditarik sampai bagian kantong sehingga ikan terkumpul di bagian kantong.

5. Ikan diangkat menggunakan serok dan dimasukkan ke dalam palka

6. Untuk mempertahankan mutu ikan, ikan yang disimpan di dalam palka diberi es curah secara berlapis dan dicampur dengan air laut.

\section{Daerah Penangkapan}

Pengoperasian jaring pukat cincin mini dilakukan di sekitar rumpon. Daerah penangkapan ini, juga merupakan daerah penangkapan bagi nelayan pancing ulur (hand line). Daerah penangkapan tersebar di Teluk Tomini dan Laut Maluku (Gambar 3). Daerah penangkapan di Teluk Tomini terutama di perairan Pangkalasean yaitu arah tenggara dari Gorontalo yang dapat ditempuh selama 24 jam dengan kecepatan kapal 7 knot/jam. Di sebelah barat daerah penangkapan ikan terdapat di perairan Kayu Bulan dan Biluhu (perjalanan 2 jam) dan di bagian selatan terdapat di perairan Bualemo, Walea dan Dolong yang dapat ditempuh selama 8 jam. Sedangkan daerah penangkapan di Laut Maluku dapat ditempuh selama 13-14 jam perjalanan dari PPI Tenda Gorontalo. Jumlah hari operasi pada umumnya 1 hingga 2 hari per trip.

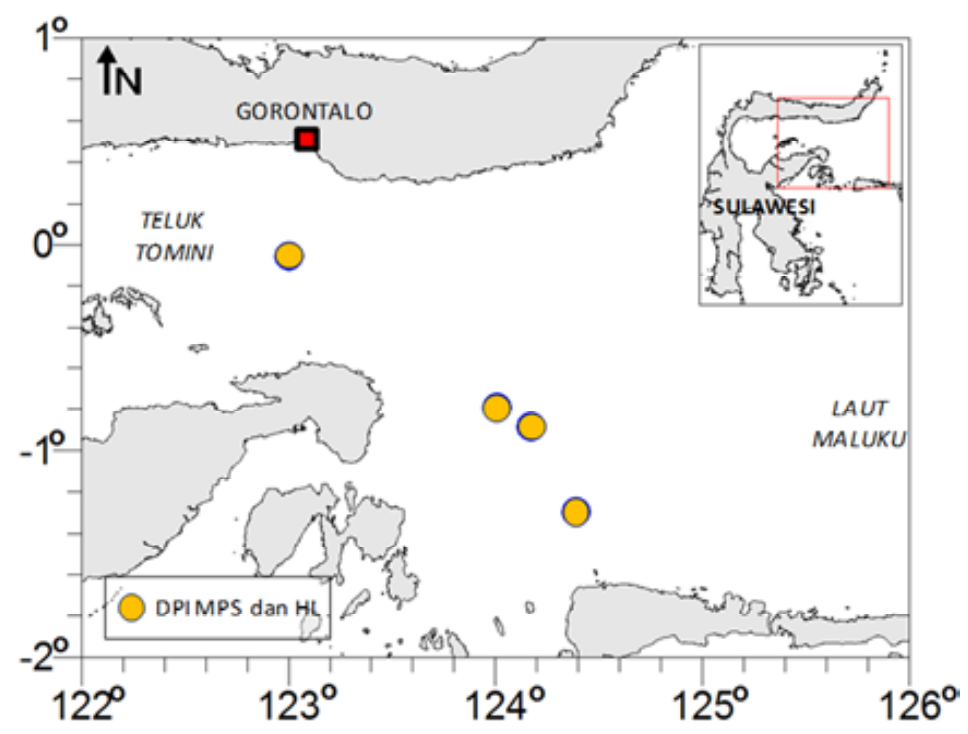

Gambar 3. Daerah penangkapan ikan alat tangkap pukat cincin mini

\section{Komposisi Hasil Tangkapan}

Hasil tangkapan pukat cincin mini dari 2 kapal contoh KM Fajar 05 dan KM Bulls Indo Raya 05 masing-masing sebanyak 2,7 ton/trip dan 7,5 ton/trip; produksi usaha pukat cincin nelayan Watampone (Sulawesi Selatan) berkisar antara 1,78 ton/trip/unit sampai dengan 7,92 ton/trip/unit (Nurdin, 2012).

Adapun komposisi jenis ikan hasil tangkapan dari kedua kapal contoh tersebut adalah jenis ikan layang biru (Decapterus macarellus) mendominasi hasil tangkapan dengan yang mencapai 6,2 ton (60\%). Jenis ikan lainnya terdiri dari tuna (Thunnus sp.) sebanyak $20 \%$, tongkol lisong (Auxis rhoceii) $15 \%$, Cakalang (Katsuwonus pelamis) $5 \%$, tongkol krai (Auxis thazard), lemadang (Coryphaena hippurus) dan ikan sunglir (Elagatis bippinulatus) yang masingmasing tertangkap dibawah 1\% (Gambar 4). Ikan tuna yang tertangkap rata-rata masih berukuran kecil (ukuran 3 ekor per kilogram). 


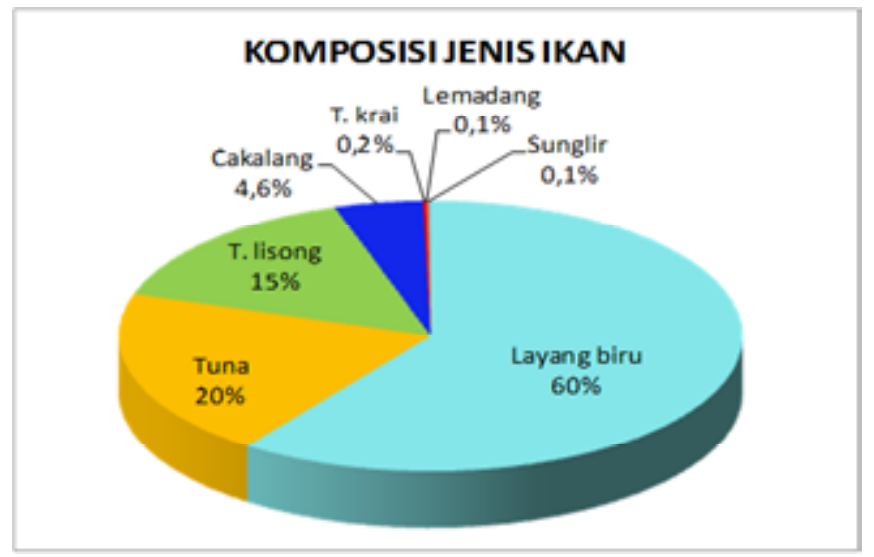

Gambar 4. Komposisi jenis ikan hasil tangkapan pukat cincin mini, Juni 2016

\section{KESIMPULAN}

1. Teknik pengoperasian pukat cincin mini dimulai dengan cara ujung jaring diturunkan diiringi dengan pergerakkan kapal melingkar mengellilingi rumpon.

2. Teknik penarikan jaring dilakukan dengan cara jaring ditarik sampai bagian kantong jaring sehingga ikan terkumpul di jaring kantong dan kemudian ikan diangkat menggunakan serok.

3. Komposisi jenis ikan hasil tangkapan pukat cincin mini di dominasi oleh jenis ikan layang biru $(60 \%)$. Jenis ikan lainnya terdiri dari tuna $(20 \%)$, tongkol lisong (15\%), Cakalang (5\%,), tongkol, lemadang, dan ikan sunglir masing-masing dibawah $1 \%$.

\section{PERSANTUNAN}

Tulisan ini merupakan bagian dari hasil kegiatan Penelitian Karakteristik Biologi Perikanan, Habitat Sumber daya dan Potensi Produksi Sumber daya Ikan di WPP 715 (Teluk Tomini, Laut Maluku, Laut Seram, Laut Halmahera dan Teluk Berau). Penanggungjawab penelitian A. Zamroni, S.Si., MSi

\section{DAFTAR PUSTAKA}

FAO, 2000. The Living Marine Resources of The Western Central Pasific. Volume 6. Bony Fishes Part 4 (Labridae to Latimeriidae), estuarine crocodiles, sea turtles, sea snakes and marine mammals). FAO Species Identification Guide For Fishery Purposes. ISSN 1020-6868: p. 3721-3764.

Nurdin E., Hufiadi dan Mahiswara, 2012. Produktivitas Usaha Penangkapan Ikan dengan Pukat Cincin (Purse Seine) di Watampone, Sulawesi Selatan dalam Status Pemanfaatan Sumber Daya Ikan di Perairan Selat Makassar, Teluk Bone, Laut Flores, Laut Banda. Hal. 137-150. 